\title{
Draft genome of Meyerozyma guilliermondii strain vka1: a yeast strain with composting potential
}

\author{
Ravisankar Valsalan and Deepu Mathew* (D)
}

\begin{abstract}
Background: Meyerozyma guilliermondii is a yeast which could be isolated from a variety of environments. The vka1 strain isolated and purified from the organic compost was found to have composting potential. To better understand the genes assisting the composting potential in this yeast, whole genome sequencing and sequence annotation were performed.

Results: The genome of M. guilliermondii vka1 strain was sequenced using a hybrid approach, on Illumina Hiseq2500 platform at 100x coverage followed by Nanopore platform at 20x coverage. The de novo assembly using dual-fold approach had given draft genome of $10.8 \mathrm{Mb}$ size. The genome was found to contain 5385 genes. The annotation of the genes was performed, and the enzymes identified to have roles in the degradation of macromolecules are discussed in relation to its composting potential. Annotation of the genome assembly of the related strains had revealed the unique biodegradation related genes in this strain. Phylogenetic analysis using the rDNA region has confirmed the position of this strain in the Ascomycota family. Raw reads are made public, and the genome wide proteome profile is presented to facilitate further studies on this organism.

Conclusions: Meyerozyma guilliermondii vka1 strain was sequenced through hybrid approach and the reads were de novo assembled. Draft genome size and the number of genes in the strain were assessed and discussed in relation to the related strains. Scientific insights into the composting potential of this strain are also presented in relation to the unique genes identified in this strain.
\end{abstract}

Keywords: Biodegradation, Genome annotation, Genome sequence, Illumina, NGS, Oxford Nanopore

\section{Background}

The yeast Meyerozyma guilliermondii (Wick.) Kurtzman and M. Suzuki, comb. nov. was first described as Endomycopsis guilliermondii by Wickerham [1]. The species was later placed in the genus Pichia, as Pichia guilliermondii [2] and recently renamed as Meyerozyma guilliermondii [3]. This ascomycetous yeast is widely distributed in the natural environment and forms part of the saprophytes on human skin and mucosal microflora. Meyerozyma caribbica (anamorph Candida fermentati) and M. guilliermondii (anamorph Candida

* Correspondence: deepu.mathew@kau.in

Bioinformatics Centre, Kerala Agricultural University, KAU Post, Thrissur, Kerala State 680 656, India

\section{Springer Open}

guilliermondii) are two closely related species $[4,5]$. This yeast has been an object of several studies, with a broad bibliography describing its multiple interesting properties and applications [6] and considered ubiquitous as they are found in deep-sea hydrothermal systems of the mid-Atlantic rift [7], wastewater treatment plants [8], maize wounds [9], and insect surfaces [10]. The yeast synthesizes large quantities of riboflavin [11] and has been extensively used in biotechnology industry.

$M$. guilliermondii is involved in xylitol production and polycyclic aromatic hydrocarbon degradation $[12,13]$. It has been used industrially for the bioremediation purposes as well as for phosphate solubilizing $[14,15]$. This

(c) The Author(s). 2020 Open Access This article is licensed under a Creative Commons Attribution 4.0 International License, which permits use, sharing, adaptation, distribution and reproduction in any medium or format, as long as you give appropriate credit to the original author(s) and the source, provide a link to the Creative Commons licence, and indicate if changes were made. The images or other third party material in this article are included in the article's Creative Commons licence, unless indicated otherwise in a credit line to the material. If material is not included in the article's Creative Commons licence and your intended use is not permitted by statutory regulation or exceeds the permitted use, you will need to obtain permission directly from the copyright holder. To view a copy of this licence, visit http://creativecommons.org/licenses/by/4.0/. 
yeast facilitates the process of tannin and saponin degradation also [16, 17].

In this study, we report the draft genome of the strain vka1 involved in the composting of organic waste. Hybrid sequencing followed by de novo assembly of the whole genome was performed. The objective of the study was to identify the number of genes in this strain and to find out and annotate the genes involved in the decomposing process, thus to give scientific back up for the biocomposting capability for this strain.

\section{Methods}

\section{Yeast isolation and DNA extraction}

The M. guilliermondii vka1 strain was isolated and purified from the organic compost at Kerala Agricultural University, India, following the standard protocol [18]. DNA was extracted according to the protocol by Dellaporta et al. [19]. For the extraction, pure culture of the yeast was isolated from the conical flask, frozen with liquid nitrogen in a mortar, ground to fine powder, and finally transferred to a tube containing extraction buffer (100 mM Tris pH 8.0, $50 \mathrm{mM}$ EDTA pH 8.0, $500 \mathrm{mM}$ $\mathrm{NaCl}, 10 \mathrm{mM}$ mercaptoethanol and $1.25 \%$ SDS). After mixing, $5 \mathrm{M}$ potassium acetate was added and incubated at $0{ }^{\circ} \mathrm{C}$ for $20 \mathrm{~min}$. Supernatant obtained after centrifugation was poured into a clean tube where genomic DNA was allowed to precipitate with isopropanol for 30 min at $-20{ }^{\circ} \mathrm{C}$. After centrifugation, pellet was resuspended in $50 \mathrm{mM}$ Tris, $10 \mathrm{mM}$ EDTA (pH 8.0) and transferred to a $20 \mu \mathrm{L}$ tube where DNA was precipitated with $80 \%$ ethanol and the dried pellet was subsequently dissolved in $10 \mathrm{mM}$ Tris, $1 \mathrm{mM}$ EDTA (pH 8.0).

The 18S rDNA gene of strain vka1 was PCR amplified and Sanger sequenced. Based on the sequence, the species of the yeast was identified. To confirm the species identity, five 18S rDNA gene sequences each from five related species (M. guilliermondii, M. caribbica, M. carpophila, Candida albicans, and C. amylolentus) were retrieved from NCBI GenBank and subjected to the cluster analysis along with our sequence, with 1000 bootstrap replications.

\section{Sequencing and assembly}

Genomic DNA was sequenced and de novo assembly of the reads was done. Sequencing was performed on Illumina Hiseq-2500 platform at $100 \times$ coverage followed by Nanopore sequencing at $20 \times$ coverage. Quality of the Illumina and Nanopore raw reads was assessed using FASTQC [20] and Poretools [21], respectively. The de novo assembly was performed using ABySS 2.2.4 [22]. Different k-mer lengths (40-190) were employed to optimize the assembly and the best k-mer value of 144 was chosen for the final output. The assembly was further conducted using SPAdes 3.11.1 [23] employing different k-mer lengths $(21,33,55,77,99$, and 111$)$, setting the --cov cutoff parameter to auto, and using the --careful option.

\section{Gene prediction and annotation}

Gene prediction from the scaffolds and annotation of these genes were performed using the following procedure. The assembly was input in to Augustus [24] using Candida guilliermondii as the trained dataset. Predicted genes were further analyzed using BLAST+ [25] and classified into different pathways using KAAS (KEGG Automatic Annotation Server) [26]. BBH (bi-directional best hit), the best method for annotating complete genomes in KEGG, was employed for the prediction, with $M$. guilliermondii selected as the organism.

\section{Analysis of genes in comparison with other strains}

To understand the genes imparting the biodegradation capability to vkal strain, its genome was compared with those of YLG18 and ATCC6260 strains. The assembled genome sequences, ASM975640v1 and ASM694215v1 of YLG18 and ATCC6260 strains, respectively, were downloaded in FASTA format from the SRA database of NCBI. The assembly was then annotated using the same pipeline detailed above.

\section{Phylogenetic analysis}

The rDNA region, comprising the complete sequence of 18S rRNA, ITS1, 5.8S rRNA, ITS2, and 28S rRNA, from vka1 strain was used as query in BLASTn and 10 sequences belonging to various genera of Ascomycota were retrieved. Sequences were then aligned using MAFFT v.7.0 using L-INS-i strategy [27] and the aligned sequences analyzed using MEGA X [28], employing NJ method with 1000 bootstrap replications. The evolutionary distances were computed using the Jukes-Cantor method.

\section{Results}

The yeast has been isolated and purified from the composted material and DNA was extracted using Dellaporta method. Purity of the DNA was good enough for sequencing. Analysis of the $18 \mathrm{~S}$ rDNA sequence has shown that the organism is M. guilliermondii. Cluster analysis with the sequences of the related yeasts had further confirmed the identity of the strain.

The Illumina results had 10,514,805 reads and the Nanopore had 261,366 reads. Raw reads were of high quality and the genome features of the strain are summarized in Table 1. Reads are made available in the NCBI SRA database under the BioProject No. PRJNA598411. Although the genome was sequenced with a combination of long and short reads for obtaining larger number of scaffolds, only a paired-end short read 
Table 1 Genome features of M. guilliermondii strain vka1

\begin{tabular}{lll}
\hline Genome & Features & Value \\
\hline M. guilliermondii strain vka1 & Reads & $1,05,14,805$ (Illumina) \\
& & $2,61,366$ (Nanopore) \\
& Scaffolds & 36 \\
& Max scaffold length & $14,99,707$ \\
& Min scaffold length & 1270 \\
& Genome size & $10.8 \mathrm{Mb}$ \\
& N50 & $5,67,598$ \\
& No. of genes & 5385 \\
\hline
\end{tabular}

library was employed in de novo assembly. The dualfold assembly approach has used ABySS 2.2.4 followed by confirmation with SPAdes 3.11 .1 assemblers. Different k-mer values were employed for obtaining the assembly and the best value was 144 . The final assembly consisted of 36 scaffolds as predicted by the assemblers. After the final assembly, draft genome with $10.8 \mathrm{Mb}$ size was obtained.

Augustus, a gene prediction program that uses a generalized hidden Markov model, was used for prediction of the genes. It has predicted 5385 genes from the vka1 strain (Table 1). KAAS annotation has classified the genes into 380 groups involved in diverse pathways (Fig. 1), of which 20 categories represented the enzymes involved in the degradation of macromolecules. The enzymes with roles in the biodegradation processes along with the list of other proteins identified in the genome are presented in Supplementary Table 1.
Comparison of the genes identified from the vka1, YLG18, and ATCC6260 strains had revealed the unique biodegradation-related genes in vka1. The enzymes S(hydroxymethyl)glutathione dehydrogenase, phenylacetate 2-hydroxylase, trimethyllysine dioxygenase, 4aminobutyrate aminotransferase, and delta3-delta2enoyl-CoA isomerase were found only in vka1 strain.

Phylogenetic analysis was carried out using the rDNA sequences of different genera belonging to Ascomycetes phylum. The phylogenetic tree had high bootstrap values for all the branches. Of the two major clades (Fig. 2), the first one had eight accessions divided into two subclusters. The first sub-cluster included Meyerozyma genus with $100 \%$ bootstrap support. Strain vka1 clustered along with M. guilliermondii strain IFM 63277. The second sub-cluster had two Debaryomyces accessions along with Candida anglica and Yamadazyma philogaea. Second major clade had three accessions, two belonging to Scheffersomyces, and one Candida palmioleophila accession forming an outgroup.

\section{Discussion}

The ascomycetous yeast M. guilliermondii is widely distributed in the environment including human body. This microbe is also exploited commercially in riboflavin and xylitol production [11]. However, it is well understood to have roles in degradation of macromolecules including polycyclic aromatic hydrocarbons [13], phosphates [15], tannins and saponins [16]. Due to these properties, it is well utilized in bioremediation [14].

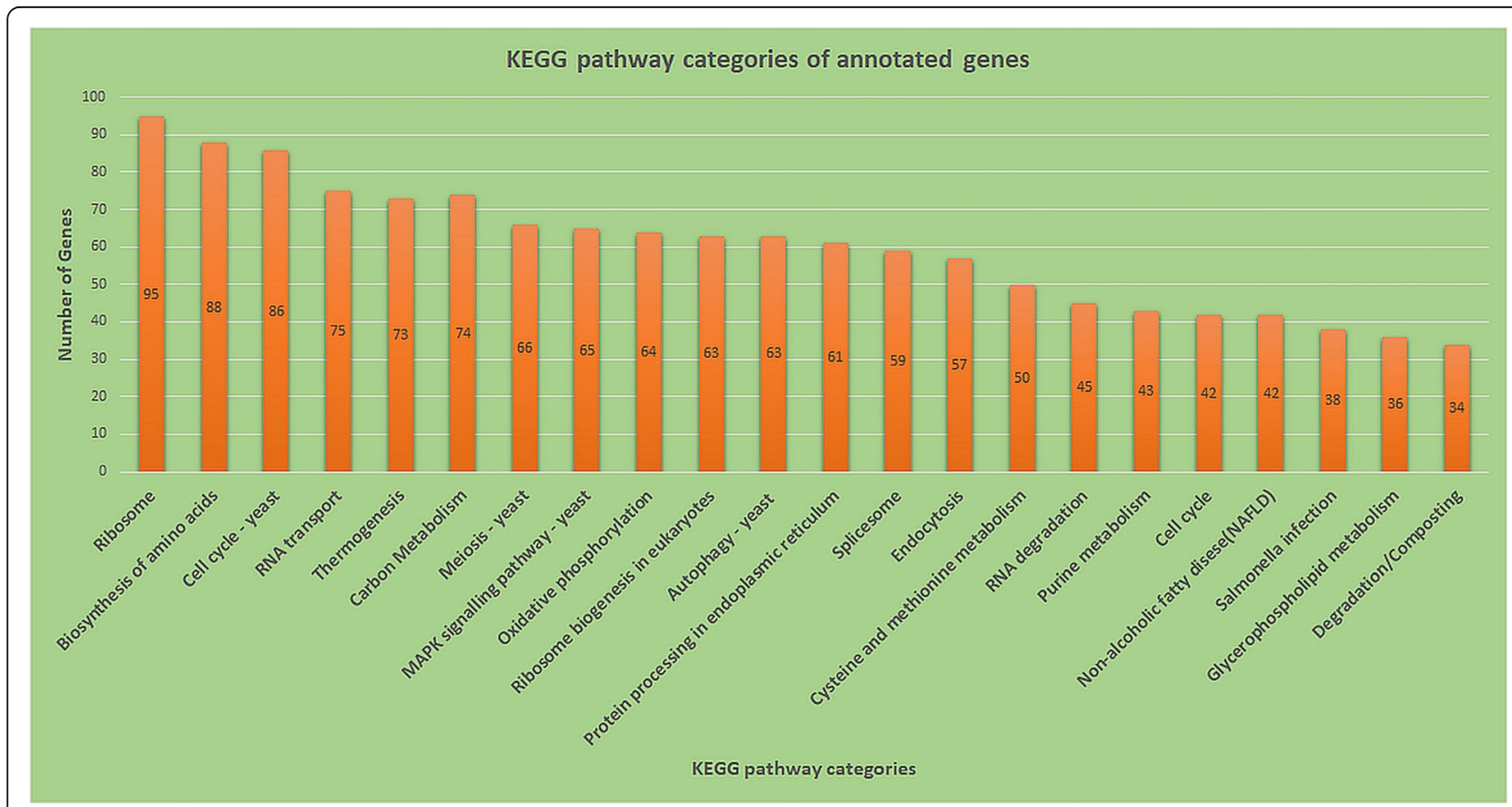

Fig. 1 Major KEGG pathway categories of annotated genes from the M. guilliermondii strain vka1 


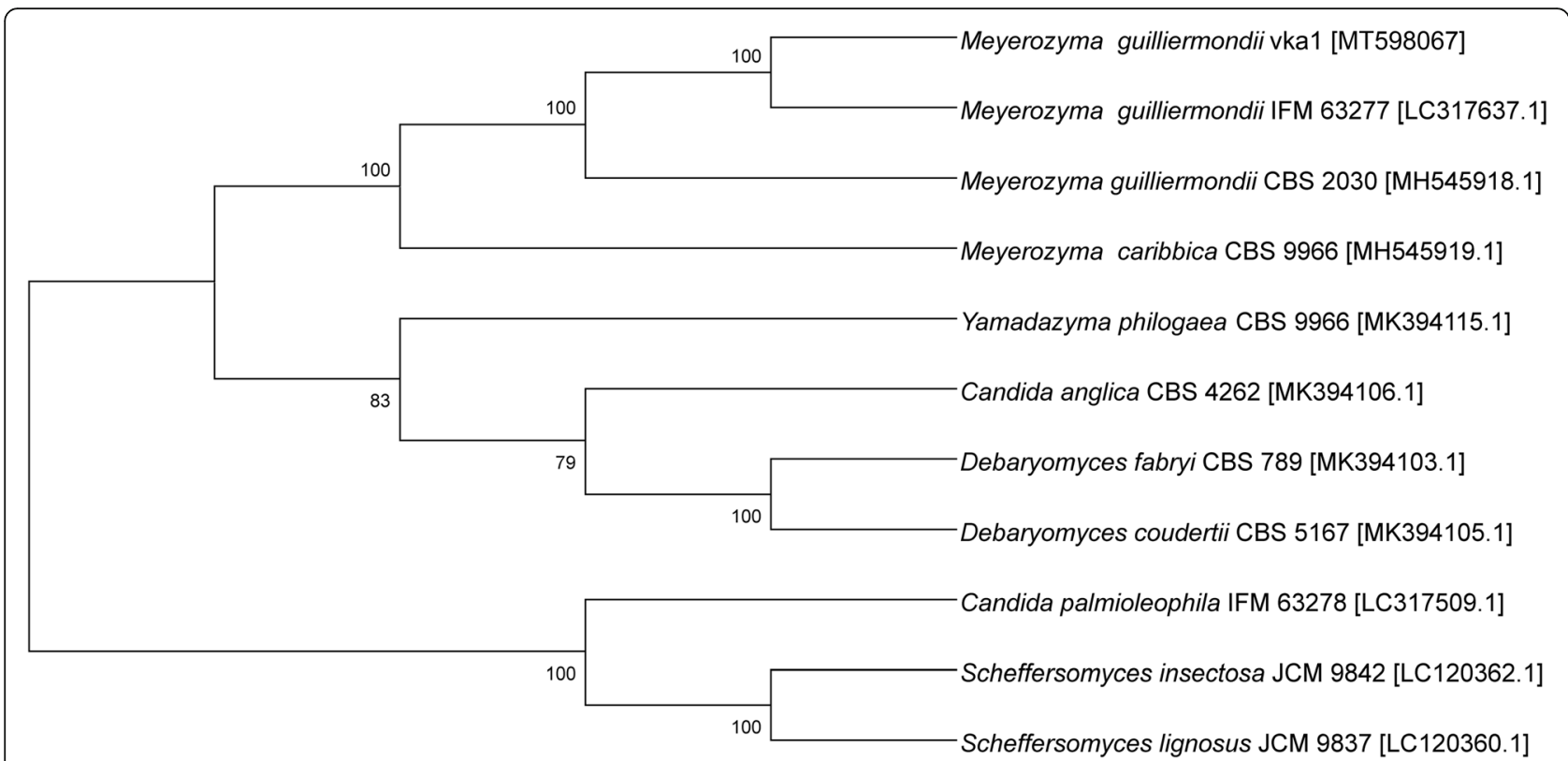

Fig. 2 Phylogenetic relationships (cladogram) based on the sequences of rDNA region from selected genomes, inferred using the Neighbour Joining (NJ) method. The percentages of replicate trees in which the associated taxa clustered together in the bootstrap test (1000 replicates) are shown next to the branches

Though Illumina sequencing platform offers better read accuracy, short read lengths is a concern [29]. On the other hand, Nanopore platform generates longer reads though comparatively error prone [30]. Method based on the combined analysis of short and long reads generated from different platforms is found to result in comprehensive genome characterization [31].

Several new de novo assembly tools have been developed recently to assemble short sequencing reads generated by next-generation sequencing platforms. Different assembly tools have their advantages and disadvantages and hence a dual-fold approach is reported to give better assemblies [32]. Thus, ABySS and SPAdes based de novo assembly was chosen in this study. The genome size shown by the assembly was slightly higher than $10.6 \mathrm{Mb}$ in M. guilliermondii strain ATCC6260 and 10.64 Mb in P. perniciosus, both sequenced on Illumina HiSeq-2500 platform [33]. The gene calling algorithm Augustus has predicted 5385 genes from the vka1 strain. The number of genes obtained is more than that in a previous study which reported 5275 genes [34], but slightly lower than 5401 genes reported by De Marco et al. [33].

Bi-directional best hit method followed in this study is identified as the best method for annotating the complete genomes [35]. The annotation had shown that the genome accommodates many enzymes which are directly involved in the biodegradation processes, explaining the composting potential of this strain. The enzyme salicylate hydroxylase is identified to be involved in decarboxylative hydroxylation [36]. Similarly, urea carboxylase is involved in carboxylation in the degradation process [37]. Enzymes cyanamide hydratase [38], phenylacetate 2-hydroxylase [39, 40], aldehyde dehydrogenase [41], saccharopine dehydrogenase [42], sarcosine oxidase [43], dihydrolipoamide dehydrogenase [44], trimethyllysine dioxygenase [45], 2-oxoglutarate dehydrogenase [44], malonate-semialdehyde dehydrogenase [46], acyl-CoA dehydrogenase [47], hydroxymethylglutarylCoA synthase [48], 3-hydroxyisobutyryl-CoA hydrolase [49], 4-aminobutyrate aminotransferase [50], S-(hydroxymethyl)glutathione dehydrogenase [51], acyl-CoA oxidase [52], delta3-delta2-enoyl-CoA isomerase [53], beta-galactosidase [54], alpha-mannosidase [55], and hexosaminidase [56] are all well understood to have direct involvement in the macromolecule catabolism. This array of macromolecule degrading enzymes, including the unique genes identified, explains the composting potential of this strain. Future studies are required on these enzymes and on this yeast to understand the mechanisms.

The phylogenetic analysis was in agreement with the previous taxonomic studies on Meyerozyma and ascomycetes. The analysis had confirmed that vka1 strain belongs to M. guilliermondii and bootstrap value of $100 \%$ affirms this result. The genera Debaryomyces, Yamadazyma, and Candida which clustered into a single clade, with the bootstrap value of $83.0 \%$, have previously been shown to be close relatives of Meyerozyma $[3,57,58]$.

\section{Conclusion}

M. guilliermondii is an ascomycetous yeast universally distributed in the natural environment and having a 
wide range of industrial applications. The draft genome of a new strain, vkal, with potential for composting the organic wastes is being reported. Hybrid sequencing followed by dual-fold assembly was used to assess the genome size and the annotation has shown the total number of genes coded. Twenty categories of enzymes which are involved in the macromolecule degradation were identified, and this wide spectrum along with the unique enzymes identified explains the composing potential of this strain. The phylogenetic analysis has confirmed its position in the Ascomycota family.

\section{Supplementary information}

Supplementary information accompanies this paper at https://doi.org/10. 1186/s43141-020-00074-2.

Additional file 1. Supplementary Table 1. Detailed results of KEGG (KAAS) analysis of Meyerozyma guilliermondii strain vka1 genome, showing the genes for the enzymes annotated and their respective categories (Categories given in boldface).

\section{Abbreviations}

EDTA: Ethylenediaminetetraacetic acid; ITS: Internal transcribed spacer; KEGG: Kyoto Encyclopedia of Genes and Genomes; MEGA: Molecular Evolutionary Genetics Analysis; NCBI: National Center for Biotechnology Information; SDS: Sodium dodecyl sulfate

\section{Acknowledgements}

Not applicable

\section{Authors' contributions}

RV did data curation, draft genome assembly, gene finding, and genome annotation. DM has isolated the yeast, isolated genomic DNA, and sequenced. All authors have read and approved the final manuscript.

\section{Funding}

This work is part of the project Distributed Information Centre, supported by Department of Biotechnology, Ministry of Science and Technology, Government of India.

\section{Availability of data and materials}

The authors declare that sequence reads associated with this article are available in the NCBI SRA database under the BioProject No. PRJNA598411.

\section{Ethics approval and consent to participate}

Not applicable

\section{Consent for publication}

Not applicable

\section{Competing interests}

The authors declare that the research was conducted with no commercial, personal, or financial relationships that could be construed as a potential conflict of interest.

Received: 11 August 2020 Accepted: 17 September 2020

Published online: 29 September 2020

\section{References}

1. Wickerham LJ, Burton KA (1954) A clarification of the relationship of Candida guilliermondii to other yeasts by a study of their mating types. $J$ Bacteriol 68(5):594-597

2. Wickerham $\sqcup$ (1966) Validation of the species Pichia guilliermondii. J Bacteriol 92(4):1269

3. Kurtzman CP, Suzuki M (2010) Phylogenetic analysis of ascomycete yeasts that form coenzyme Q-9 and the proposal of the new genera Babjeviella,
Meyerozyma, Millerozyma, Priceomyces, and Scheffersomyces. Mycoscience 51: 2-14. https://doi.org/10.1007/s10267-009-0011-5

4. Bai FY, Liang HY, Jia JH (2000) Taxonomic relationships among the taxa in the Candida guilliermondii complex, as revealed by comparative electrophoretic karyotyping. Int J Syst Evol Microbiol 50(Pt 1):417-422. https://doi.org/10.1099/00207713-50-1-417

5. Vaughan-Martini A, Kurtzman CP, Meyer SA, O'Neill EB (2005) Two new species in the Pichia guilliermondii clade: Pichia caribbica sp. nov., the ascosporic state of Candida fermentati, and Candida carpophila comb. nov. FEMS Yeast Res 5(4-5):463-469. https://doi.org/10.1016/j.femsyr.2004.10.008

6. Papon N, Savini V, Lanoue A, Simkin AJ, Creche J, Giglioli-Guivarc'h N et al (2013) Candida guilliermondii: biotechnological applications, perspectives for biological control, emerging clinical importance and recent advances in genetics. Curr Genet 59(3):73-90. https://doi.org/10.1007/s00294-013-0391-0

7. Gadanho M, Sampaio J (2005) Occurrence and diversity of yeasts in the mid-Atlantic ridge hydrothermal fields near the Azores Archipelago. Microb Ecol 50:408-417. https://doi.org/10.1007/s00248-005-0195-y

8. Lahav R, Fareleira P, Nejidat A, Abeliovich A (2002) The identification and characterization of osmotolerant yeast isolates from chemical wastewater evaporation ponds. Microb Ecol 43(3):388-396. https://doi.org/10.1007/ s00248-002-2001-4

9. Nout MJ, Platis CE, Wicklow DT (1997) Biodiversity of yeasts from Illinois maize. Can J Microbiol 43(4):362-367. https://doi.org/10.1139/m97-050

10. Suh SO, Blackwell M (2004) Three new beetle-associated yeast species in the Pichia guilliermondii clade. FEMS Yeast Res 5(1):87-95. https://doi.org/10. 1016/j.femsyr.2004.06.001

11. Protchenko OV, Boretsky Yu R, Romanyuk TM, Fedorovych DV (2000) Oversynthesis of riboflavin by yeast Pichia guilliermondii in response to oxidative stress. Ukr Biokhim Zh 72(2):19-23

12. Hesham AEL, Khan S, Liu X, Zhang Y, Wang Z, Yang M (2006) Application of PCR-DGGE to analyse the yeast population dynamics in slurry reactors during degradation of polycyclic aromatic hydrocarbons in weathered oil. Yeast 23(12):879-887. https://doi.org/10.1002/yea.1401

13. Mussatto SI, Silva CJ, Roberto IC (2006) Fermentation performance of Candida guilliermondii for xylitol production on single and mixed substrate media. Appl Microbiol Biotechnol 72(4):681-686. https://doi.org/10.1007/ s00253-006-0372-z

14. Carmona FJ, Pascual J, Felix F (2018) Targeted composting of olive mil wastes. Comparison between three-phase and two-phase waste composting. In: Proceedings of 6th International Conference on Sustainable Solid Waste Management (NAXOS2018), 13-16 June 2018. Poster, Naxos Island, p 32

15. Ganapathy B, Yahya A, Ibrahim N (2019) Bioremediation of palm oil mill effluent (POME) using indigenous Meyerozyma guilliermondii. Environ Sci Pollut Res 26(11):1113-11125. https://doi.org/10.1007/s11356-019-04334-8

16. Zhang J, Ying Y, Li X, Yao X (2020a) Changes in tannin and saponin components during co-composting of Camellia oleifera Abel shell and seed cake. PLoS ONE 15(3):e0230602. https://doi.org/10.1371/journal.pone.0230602

17. Zhang J, Ying Y, Yao X, Huang W, Tao XJB (2020b) Degradations of tannin and saponin and changes in nutrition during co-composting of shell and seed cake of Camellia oleifera Abel. BioResources 15(2):2721-2734

18. Choi GW, Um HJ, Kim Y, Kang HW, Kim M, Chung BW, Kim YH (2010) Isolation and characterization of two soil derived yeasts for bioethanol production on cassava starch. Biomass Bioenergy 34(8):1223-1231. https:// doi.org/10.1016/j.biombioe.2010.03.019

19. Dellaporta SL, Wood J, Hicks JB (1983) A plant DNA minipreparation: Version II. Plant Mol Biol Report 1(4):19-21. https://doi.org/10.1007/BF02712670

20. Andrews S (2010) FastQC: a quality control tool for high throughput sequence data. In: Babraham Bioinformatics, Babraham Institute, Cambridge, United Kingdom, available at http://www.bioinformatics.babraham.ac.uk/ projects/fastqc/

21. Loman NJ, Quinlan AR (2014) Poretools: a toolkit for analyzing nanopore sequence data. Bioinformatics 30(23):3399-3401. https://doi.org/10.1093/ bioinformatics/btu555

22. Simpson JT, Wong K, Jackman SD, Schein JE, Jones SJ, Birol I (2009) ABySS: a parallel assembler for short read sequence data. Genome Res 19(6):11171123. https://doi.org/10.1101/gr.089532.108

23. Bankevich A, Nurk S, Antipov D, Gurevich AA, Dvorkin M, Kulikov AS et al (2012) SPAdes: a new genome assembly algorithm and its applications to single-cell sequencing. J Comput Biol 19(5):455-477. https://doi.org/10.1089/ cmb.2012.0021 
24. Stanke M, Diekhans M, Baertsch R, Haussler D (2008) Using native and syntenically mapped cDNA alignments to improve de novo gene finding. Bioinformatics 24(5):637-644. https://doi.org/10.1093/bioinformatics/btn013

25. Camacho C, Coulouris G, Avagyan V, Ma N, Papadopoulos J, Bealer K, Madden TL (2009) BLAST+: architecture and applications. BMC Bioinformatics 10:421. https://doi.org/10.1186/1471-2105-10-421

26. Moriya Y, Itoh M, Okuda S, Yoshizawa AC, Kanehisa M (2007) KAAS: an automatic genome annotation and pathway reconstruction server. Nucleic Acids Res 35(Web Server issue):W182-185. https://doi.org/10.1093/nar/gkm321

27. Katoh K, Rozewicki J, Yamada KD (2019) MAFFT online service: multiple sequence alignment, interactive sequence choice and visualization. Brief Bioinform 20(4):1160-1166. https://doi.org/10.1093/bib/bbx108

28. Kumar S, Stecher G, Li M, Knyaz C, Tamura K (2018) MEGA X: Molecular Evolutionary Genetics Analysis across Computing Platforms. Mol Biol Evol 35(6):1547-1549. https://doi.org/10.1093/molbev/msy096

29. Kircher M, Heyn P, Kelso J (2011) Addressing challenges in the production and analysis of illumina sequencing data. BMC Genomics 12(1):382. https:// doi.org/10.1186/1471-2164-12-382

30. Laver T, Harrison J, O'neill PA, Moore K, Farbos A, Paszkiewicz K, Studholme DJ (2015) Assessing the performance of the oxford nanopore technologies minion. Biomol Detect Quantif 3:1-8. https://doi.org/10.1016/j.bdq.2015.02.001

31. Au KF, Sebastiano V, Afshar PT, Durruthy JD, Lee L, Williams BA, van Bakel H, Schadt EE, Reijo-Pera RA, Underwood JG, Wong WH (2013) Characterization of the human ESC transcriptome by hybrid sequencing. Proc Natl Acad Sci U S A 110(50):E4821-E4830. https://doi.org/10.1073/pnas.1320101110

32. Lin Y, Li J, Shen H, Zhang L, Papasian CJ, Deng HW (2011) Comparative studies of de novo assembly tools for next-generation sequencing technologies. Bioinformatics 27(15):2031-2037. https://doi.org/10.1093/ bioinformatics/btr319

33. De Marco L, Epis S, Capone A, Martin E, Bozic J, Crotti E, Ricci I, Sassera D (2018) The genomes of four Meyerozyma caribbica isolates and novel insights into the Meyerozyma guilliermondii species complex. G3 (Bethesda) 8(3):755-759. https://doi.org/10.1534/g3.117.300316

34. Yan W, Zhang S, Wu M, Zhang W, Zhou J, Dong W et al (2019) The draft genome sequence of Meyerozyma guilliermondii strain YLG18, a yeast capable of producing and tolerating high concentration of 2-phenylethanol. 3. Biotech 9(12):441. https://doi.org/10.1007/s13205-019-1975-2

35. Aoki-Kinoshita KF, Kanehisa M (2007) Gene annotation and pathway mapping in KEGG. In: Comparative Genomics, Bergman, N. H. (ed.), Methods in Molecular Biology vol. 396, ISBN 978-1-934115-37-4, Humana Press, pp. 71-91. doi: https://doi.org/10.1007/978-1-59745-515-2_6

36. You IS, Ghosal D, Gunsalus IC (1991) Nucleotide sequence analysis of the Pseudomonas putida PpG7 salicylate hydroxylase gene (nahG) and its 3'flanking region. Biochemistry 30(6):1635-1641. https://doi.org/10.1021/ bi00220a028

37. Kanamori T, Kanou N, Atomi H, Imanaka T (2004) Enzymatic characterization of a prokaryotic urea carboxylase. J Bacteriol 186(9):2532-2539. https://doi. org/10.1128/jb.186.9.2532-2539.2004

38. Li J, Biss M, Fu Y, Xu X, Moore SA, Xiao W (2015) Two duplicated genes DDI2 and DDI3 in budding yeast encode a cyanamide hydratase and are induced by cyanamide. J Biol Chem 290(20):12664-12675. https://doi.org/ 10.1074/jbc.M1 15.645408

39. Mingot JM, Peñalva MA, Fernández-Cañón JM (1999) Disruption of phacA, an Aspergillus nidulans gene encoding a novel cytochrome P450 monooxygenase catalyzing phenylacetate 2-hydroxylation, results in penicillin overproduction. J Biol Chem 274(21):14545-14550. https://doi.org/ 10.1074/jbc.274.21.14545

40. Rodríguez-Sáiz M, Barredo JL, Moreno MA, Fernández-Cañón JM, Peñalva MA, Díez B (2001) Reduced function of a phenylacetate-oxidizing cytochrome p450 caused strong genetic improvement in early phylogeny of penicillin-producing strains. J Bacteriol 183(19):5465-5471. https://doi.org/ 10.1128/jb.183.19.5465-5471.2001

41. Ohta T, Tani A, Kimbara K, Kawai F (2005) A novel nicotinoprotein aldehyde dehydrogenase involved in polyethylene glycol degradation. Appl Microbio Biotechnol 68(5):639-646. https://doi.org/10.1007/s00253-005-1936-z

42. Gaziola SA, Sodek L, Arruda P, Lea PJ, Azevedo RA (2000) Degradation of lysine in rice seeds: Effect of calcium, ionic strength, S-adenosylmethionine and S-2-aminoethyl- I-cysteine on the lysine 2-oxoglutarate reductasesaccharopine dehydrogenase bifunctional enzyme. Physiol Plant 110(2):164171. https://doi.org/10.1034/j.1399-3054.2000.110204.x
43. Kim JM, Shimizu S, Yamada H (1986) Sarcosine oxidase involved in creatinine degradation in Alcaligenes denitrificans subsp. denitrificans J9 and Arthrobacter spp. J5 and J11. Agric Biol Chem 50(11):2811-2816. https://doi. org/10.1080/00021369.1986.10867841

44. Oppermann FB, Schmidt B, Steinbüchel A (1991) Purification and characterization of acetoin:2,6-dichlorophenolindophenol oxidoreductase, dihydrolipoamide dehydrogenase, and dihydrolipoamide acetyltransferase of the Pelobacter carbinolicus acetoin dehydrogenase enzyme system. J Bacteriol 173(2):757-767. https://doi.org/10.1128/jb.173.2.757-767.1991

45. van Vlies N, Ofman R, Wanders RJ, Vaz FM (2007) Submitochondrial localization of 6-N-trimethyllysine dioxygenase-implications for carnitine biosynthesis. FEBS J 274(22):5845-5851. https://doi.org/10.1111/j.1742-4658. 2007.06108.x

46. Goodwin GW, Rougraff PM, Davis EJ, Harris RA (1989) Purification and characterization of methylmalonate-semialdehyde dehydrogenase from rat liver. Identity to malonate-semialdehyde dehydrogenase. J Biol Chem 264(25):14965-14971

47. Corydon TJ, Bross P, Jensen TG, Corydon MJ, Lund TB, Jensen UB et al (1998) Rapid degradation of short-chain Acyl-CoA Dehydrogenase variants with temperature-sensitive folding defects occurs after import into mitochondria. J Biol Chem 273(21):13065-13071. https://doi.org/10.1074/jbc. 273.21.13065

48. Shinohara $M$, Sato $N$, Kurinami $H$, Takeuchi D, Takeda S, Shimamura M et al (2010) Reduction of brain $\beta$-amyloid (A $\beta$ ) by Fluvastatin, a Hydroxymethylglutaryl-CoA Reductase inhibitor, through increase in degradation of amyloid precursor protein C-terminal fragments (APP-CTFs) and A $\beta$ clearance. J Biol Chem 285(29):22091-22102. https://doi.org/10. 1074/jbc.M110.102277

49. Pan Y, Yang J, Gong Y, Li X, Hu H (2017) 3-Hydroxyisobutyryl-CoA hydrolase involved in isoleucine catabolism regulates triacylglycerol accumulation in Phaeodactylum tricornutum. Philos Trans R Soc Lond Ser B Biol Sci 372(1728):20160409. https://doi.org/10.1098/rstb.2016.0409

50. Large PJ, Robertson A (1988) The subcellular location of 4-aminobutyrate aminotransferase in Candida boidinii and its probable role in the breakdown of putrescine and spermidine. Yeast 4(2):149-153. https://doi.org/10.1002/ yea.320040209

51. Koopman F, Wierckx N, de Winde JH, Ruijssenaars HJ (2010) Identification and characterization of the furfural and 5-(hydroxymethyl)furfural degradation pathways of Cupriavidus basilensis HMF14. Proc Natl Acad Sci U S A 107(11):4919. https://doi.org/10.1073/pnas.0913039107

52. Dommes V, Baumgart C, Kunau WH (1981) Degradation of unsaturated fatty acids in peroxisomes. Existence of a 2,4-dienoyl-CoA reductase pathway. J Biol Chem 256(16):8259-8262

53. Palosaari PM, Hiltunen JK (1990) Peroxisomal bifunctional protein from rat liver is a trifunctional enzyme possessing 2-enoyl-CoA hydratase, 3hydroxyacyl-CoA dehydrogenase, and delta 3, delta 2-enoyl-CoA isomerase activities. J Biol Chem 265(5):2446-2449

54. Kitamikado M, Ito M, Li YT (1981) Isolation and characterization of a keratan sulfate-degrading endo-beta-galactosidase from Flavobacterium keratolyticus. Jiol Chem 256(8):3906-3909

55. De Gasperi R, Daniel PF, Warren CD (1992) A human lysosomal alphamannosidase specific for the core of complex glycans. J Biol Chem 267(14): 9706-9712

56. Conzelmann E, Sandhoff K (1978) AB variant of infantile GM2 gangliosidosis: deficiency of a factor necessary for stimulation of hexosaminidase Acatalyzed degradation of ganglioside GM2 and glycolipid GA2. Proc Natl Acad Sci U S A 75(8):3979. https://doi.org/10.1073/pnas.75.8.3979

57. Butler G, Rasmussen MD, Lin MF, Santos MA, Sakthikumar S, Munro CA, Rheinbay E, Grabherr M, Forche A, Reedy JL et al (2009) Evolution of pathogenicity and sexual reproduction in eight Candida genomes. Nature 459(7247):657-662. https://doi.org/10.1038/nature08064

58. Kurtzman CP, Robnett CJ (2013) Relationships among genera of the Saccharomycotina (Ascomycota) from multigene phylogenetic analysis of type species. FEMS Yeast Res 13(1):23-33. https://doi.org/10.1111/1567-1364. 12006

\section{Publisher's Note}

Springer Nature remains neutral with regard to jurisdictional claims in published maps and institutional affiliations. 